\title{
Foot pain: common, of consequence, and consulted about
}

\author{
Edward Roddy \\ From Australasian Podiatry Council Conference 2011 \\ Melbourne, Australia. 26-29 April 2011
}

Foot pain is highly prevalent in the community. Foot pain and ankle pain occurring on most days are reported by $25 \%$ and $15 \%$ of older adults, respectively. Both foot and ankle pain are more prevalent in women than men but no consistent relationship with age has been identified. Pain within the foot most commonly occurs at the toes or forefoot, followed by the arch or ball, with the heel and hindfoot least frequently affected.

Foot pain is commonly associated with locomotor disability. Almost two-thirds of adults aged 50 years and over with foot pain report problems related to physical function. Eight percent of older adults without disabling foot pain experience its onset over a three-year period whereas resolution appears to be uncommon, with $70 \%$ of those with disabling symptoms still having them three years later. Onset of physical impairment associated with foot pain most commonly relates to increased reliance on vehicular transport, and difficulty walking and standing. Furthermore, foot pain is also associated with poor balance and risk of falling.

Although musculoskeletal foot problems account for a substantial number of consultations in primary care, it appears that only a minority of people with foot problems consult about them. Eight percent of primary care musculoskeletal consultations (290 primary care consultations per 10,000 registered patients per year) involve musculoskeletal foot problems. However, only $20 \%$ of people with musculoskeletal foot problems see their family doctor over a three-year period and a similar proportion of those with foot pain see a podiatrist over twelve months. Primary care consultation with a musculoskeletal foot problem is more likely in those with foot pain, those who consult frequently about other problems, and those who believe effective treatments are

Correspondence: e.roddy@cphc.keele.ac.uk

Arthritis Research UK Primary Care Centre, Keele University, Staffordshire, ST5 $5 B G$, UK

\section{Ciomed Central}

(c) 2011 Roddy; licensee BioMed Central Ltd. This is an open access article distributed under the terms of the Creative Commons Attribution License (http://creativecommons.org/licenses/by/2.0), which permits unrestricted use, distribution, and reproduction in any medium, provided the original work is properly cited. available. Most primary care consultations for musculoskeletal foot problems are categorized by family doctors using non-specific terms describing pain location, eg foot pain or ankle pain, with specific diagnostic codes, eg plantar fasciitis, used less frequently.

In summary, foot pain is a common problem both in the community and in primary care, and frequently associates with locomotor disability. However, only a small proportion of those with musculoskeletal foot problems consult about them. Further studies are needed to explore why people choose to consult a particular health care professional about their foot problem, how the decision to consult can be influenced, and how foot pain and problems are managed in different healthcare settings.

Published: 20 May 2011

doi:10.1186/1757-1146-4-S1-A7

Cite this article as: Roddy: Foot pain: common, of consequence, and consulted about. Journal of Foot and Ankle Research 2011 4(Suppl 1):A7.

Submit your next manuscript to BioMed Central and take full advantage of:

- Convenient online submission

- Thorough peer review

- No space constraints or color figure charges

- Immediate publication on acceptance

- Inclusion in PubMed, CAS, Scopus and Google Scholar

- Research which is freely available for redistribution

Submit your manuscript at Submit your manuscript at C BioMed Central 